\title{
Burnout Among Orthopedic Surgeons and Residents in Pakistan
}

Adeel A. Siddiqui ${ }^{1}$, Muhammad Jamil ${ }^{2}$, Ghulam M. Kaimkhani ${ }^{1}$, Malik Wasim ${ }^{2}$, Muhammad Soughat Katto $^{2}$, Uzair Yaqoob ${ }^{3}$, Mariyam Adeel $^{4}$

1. Orthopedic Surgery, Dow University of Health Sciences, Karachi, PAK 2. Orthopedic Surgery, Civil Hospital, Karachi, PAK 3. Surgery, Jinnah Postgraduate Medical Centre, Karachi, PAK 4. Dow Medical College, Dow University of Health Sciences, Karachi, PAK

Corresponding author: Uzair Yaqoob, ozair_91393@hotmail.com

\section{Abstract \\ Objective}

Burnout is exceptionally pervasive among medical professionals, especially surgeons, and is considered the main indicator of surgeons' fulfillment with career choice. Our objectives are to discover the extent of orthopedic specialist burnout in Pakistan and to explore the clinical impact of burnout. The efficacy of surgeons may be enhanced by implementing burnout prevention and treatment plans.

\section{Data collection}

This observational study was conducted from April 2018 to May 2018 in various tertiary care hospitals in Pakistan and includes post-graduate trainees and consultants. Those who agreed to be part of this study were asked to complete a self-structured questionnaire about demographics and burnout. The questionnaire had 28 questions based on a standard questionnaire from the American Public Welfare Association.

\section{Results}

In our study, $15 \%(n=15)$ of respondents had advance burnout, $22 \%(n=22)$ had early burnout, and $43 \%(n=49)$ had a fair chance of burnout. All 15 participants suffering from advance burnout were consultants. Of participants suffering from early burnout, $36.3 \%(n=8)$ were consultants, and $63.7 \%(n=14)$ were postgraduate trainees.

\section{Conclusion}

Compared to other countries, the burnout rate is higher among Pakistani orthopedic surgeons. Special care and attention should be paid towards the stress and workload of surgeons.

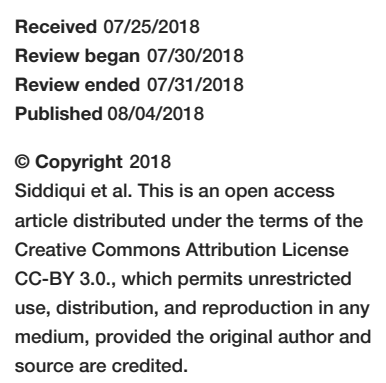
source are credited.
Categories: Orthopedics, Healthcare Technology, Epidemiology/Public Health Keywords: burnout, pakistan, physician, stress, orthopedics, surgeons

\section{Introduction}

Burnout is very prevalent among surgeons and is considered the most important predictor of surgeons' satisfaction with career and specialty choice [1]. Burnout is a syndrome defined by three aspects: emotional exhaustion, depersonalization, and low job satisfaction [2]. Burnout syndrome is associated with poor outcomes for both patients and institutions and has serious consequences for the surgeon [3]. Various studies have shown that the rates of burnout in orthopedic surgeons are higher than those in the general population and various other medical subspecialties [2-3]. The training and practice of orthopedic surgery are hectic and demanding, contributing to burnout development among surgeons and trainees in the field of orthopedics [3].

A search of the literature showed that burnout rates among orthopedic surgeons are in the range of $50 \%$ to $60 \%$, which is very high compared with other surgeons. Residents have the highest rate of burnout, followed by heads of department, then faculty members [3]. According to another study, "residents reported considerable burnout, showing a high level of emotional exhaustion and depersonalization, and an average level of personal achievement, whereas faculty reported minimal burnout, showing a low level of emotional exhaustion $(\mathrm{P}<.0003)$, an average level of depersonalization $(\mathrm{P}<.0001)$, and a high level of personal achievement $(\mathrm{P}<.0001)$ " [4]. Though various studies have shown heavy burnout rates among orthopedic surgeons, very little work regarding its risk factors and prevention has been done. Factors responsible for burnout among various orthopedic surgeon populations should be pointed out [3].

The objective of our study is to find the proportion of orthopedic surgeons experiencing burnout in Pakistan to focus on identifying the signs of burnout and implementing prevention and treatment programs to 


\section{Cureus}

increase surgeons' efficacy and decrease patient mortality.

\section{Materials And Methods}

This observational study was conducted from April 2018 to May 2018 in four major tertiary care hospitals in Pakistan including the Civil Hospital, Karachi, Jinnah Postgraduate Medical Center, Karachi, Jinnah Hospital Lahore, Darul Sehat Hospital, Karachi, and with consultants from some other private sector hospitals. One hundred fifty questionnaires were distributed, and 100 questionnaires were returned completed; the response rate was $66 \%$. Those who agreed to be part of this study were asked to complete a self-structured questionnaire about demographics and burnout. The questionnaire had 28 questions based on the standard questionnaire from the American Public Welfare Association. The questionnaire had standard result criteria and burnout grades ranging from grade I to grade $\mathrm{V}$ (Table 1) [5].

\begin{tabular}{|c|c|c|}
\hline Grade of burnout & Scores & Inference \\
\hline 1 & 28-38 & No stress or professional burnout \\
\hline II & 38-50 & Stress but no professional burnout \\
\hline III & 51-70 & Fair chance of burnout \\
\hline IV & 71-90 & Early burnout \\
\hline V & $90+$ & Advanced burnout \\
\hline
\end{tabular}

\section{TABLE 1: American Public Welfare Association grades of burnout}

A descriptive analysis was performed using IBM Statistical Package for the Social Sciences (SPSS) Statistics for Windows, Version 21.0. (IBM Corp., Armonk, NY). The frequency of various grades of burnout was calculated. Stratification was done according to sector and position.

\section{Results}

A total of 100 participants were included in the study, of whom $42 \%$ were consultants, and $58 \%$ were postgraduate trainees. A total of $33 \%$ of the participants practiced only in the public sector, $26 \%$ practiced only in the private sector, and $41 \%$ practiced in both public and private sector hospitals. Of the participants, $15 \%$ had advance burnout, $22 \%$ had early burnout, and $43 \%$ had a fair chance of burnout (Table 2).

\begin{tabular}{|c|c|c|}
\hline Grade of burnout & Frequency (n) & Percentage \\
\hline No stress or professional burnout & 2 & $2 \%$ \\
\hline Stress but no professional burnout & 18 & $18 \%$ \\
\hline Fair chance of burnout & 43 & $43 \%$ \\
\hline Early burnout & 22 & $22 \%$ \\
\hline Advanced burnout & 15 & $15 \%$ \\
\hline
\end{tabular}

TABLE 2: Frequency of grades of burnout

All 15 participants suffering from advance burnout were consultants. Of participants suffering from early burnout, 36.3\% $(n=8)$ were consultants, and $63.7 \%(n=14)$ were post-graduate trainees (Table 3). 


\section{Cureus}

\begin{tabular}{|c|c|c|}
\hline \multirow{2}{*}{ Grades of burnout } & \multicolumn{2}{|l|}{ Designation } \\
\hline & Consultant (\%) & Post-graduate trainee (\%) \\
\hline No stress or professional burnout & $0(0 \%)$ & $2(100 \%)$ \\
\hline Stress but no professional burnout & $5(27.7 \%)$ & $13(72.3 \%)$ \\
\hline Fair chance of burnout & 14 (30.5\%) & 29 (69.5\%) \\
\hline Early burnout & $8(36.3 \%)$ & $14(63.7 \%)$ \\
\hline Advanced burnout & $15(100 \%)$ & $0(0 \%)$ \\
\hline Total & 42 & 58 \\
\hline
\end{tabular}

\section{TABLE 3: Burnout by designation}

Of doctors suffering from advance burnout, $40 \%(\mathrm{n}=6)$ work exclusively in the public sector, $26.6 \%(\mathrm{n}=4)$ work in the private sector only, and $33.3 \%(n=5)$ work in both sectors (Table 4$)$.

\begin{tabular}{|c|c|c|c|}
\hline \multirow{2}{*}{ Grades of burnout } & \multicolumn{3}{|l|}{ Sector } \\
\hline & Public & Private & Both \\
\hline No stress or professional burnout & 0 & 2 & 0 \\
\hline Stress but no professional burnout & 2 & 6 & 10 \\
\hline Fair chances of burnout & 18 & 10 & 15 \\
\hline Early burnout & 8 & 3 & 11 \\
\hline Advanced burnout & 6 & 4 & 5 \\
\hline Total & 34 & 26 & 41 \\
\hline
\end{tabular}

TABLE 4: Burnout by sector

Among the surgeons, $60 \%(\mathrm{n}=60)$ feel they suffer from burnout, $30 \%(\mathrm{n}=30)$ said they do not feel they are burning out and $10 \%(n=10)$ answered that they do not know. When asked why they were burning out, $42 \%$ $(n=42)$ of the doctors blamed their workload for their burnout, while another $28 \%(n=28)$ said it was because of low wages they felt burnout (Table 5).

\begin{tabular}{|c|c|c|}
\hline Reasons for burnout & Frequency (n) & Percentage \\
\hline Long hours & 15 & $15 \%$ \\
\hline Work environment & 6 & $6 \%$ \\
\hline Workload & 42 & $42 \%$ \\
\hline Low wages & 28 & $28 \%$ \\
\hline Other & 9 & $9 \%$ \\
\hline
\end{tabular}

TABLE 5: Reasons for burnout

\section{Discussion}

In our study, $15 \%$ of orthopedic surgeons were suffering from advance burnout, $22 \%$ showed early burnout, and $43 \%$ had a fair chance of burnout. In general, doctors working in the public sector had a higher burnout 
According to a review published in 2013, 50\% to $60 \%$ of orthopedic surgeons suffer from burnout [3]. In our study, the burnout rate among Pakistani orthopedic surgeons was found to be $80 \%$. This is alarming considering the burnout rates among Indian orthopedic surgeons is $23 \%$ [6]. According to our study, $73 \%$ of post-graduate trainees had burnout while $53 \%$ of Australian orthopedic, and 50\% of American post-graduate trainees are burned out [7-8]. In our study, all the participants with advance burnout were consultants, and $88 \%$ had a burnout score from grade III-V. A 2009 study found that $38 \%$ of consultants have high emotional exhaustion [9].

In our study, participants cited workload and low wages as prime reasons for their burnout. This is consistent with other studies which also lists similar reasons. In a cross-sectional study, Chou et al. found that workload was the prime reasons for doctors feeling burnout [10]. Some studies suggested a lack of decision-making authority, difficulty balancing personal and professional life, excessive paperwork, and high patient volume are the greatest sources of stress [11-14].

Burnout can affect physicians' satisfaction with their work and can affect their patients' health and quality of life. The need for identifying the signs of burnout and implementing prevention and treatment programs is important among orthopedic residency programs and departments. Emerging evidence indicates that mind-based interventions or educational programs combined with meditation may be effective modes of management [14].

This study is the first of its type in the Pakistani population, to the best of our knowledge. However, there are limitations. First, the study has a relatively small sample size. A larger study is required to better evaluate the frequency of orthopedic surgeons suffering from burnout. Second, stressful life events and personal problems that may also influence the prevalence of burnout, as noted by various other studies, were not considered in this research. Finally, as this study was conducted with a cross-sectional design, the causal relationship is weak. A cohort follow-up study on the condition of surgeon burnout is necessary to further validate the finding of this study.

\section{Conclusions}

Burnout rate among healthcare professionals, especially surgeons and those in the field of orthopedic surgery, is relatively high in Pakistan. Special care and attention should be paid to the stress levels and workloads of surgeons. Efforts should be made to implement strategies for prevention and treatment of this condition to improve healthcare environment efficiency.

\section{Additional Information}

\section{Disclosures}

Human subjects: Consent was obtained by all participants in this study. Civil Hospital Karachi, Jinnah Post graduate medical center Karachi, Jinnah Hospital Lahore, Dar-ul-sehat hospital issued approval NA. Animal subjects: All authors have confirmed that this study did not involve animal subjects or tissue. Conflicts of interest: In compliance with the ICMJE uniform disclosure form, all authors declare the following: Payment/services info: All authors have declared that no financial support was received from any organization for the submitted work. Financial relationships: All authors have declared that they have no financial relationships at present or within the previous three years with any organizations that might have an interest in the submitted work. Other relationships: All authors have declared that there are no other relationships or activities that could appear to have influenced the submitted work.

\section{References}

1. Dimou FM, Eckelbarger D, Riall TS: Surgeon burnout: A systematic review. J Am Coll Surg. 2016, 222:1230-9. 10.1016/j.jamcollsurg.2016.03.022

2. Daniels AH, DePasse JM, Kamal RN: Orthopaedic surgeon burnout. J Am Acad Orthop Surg. 2016, 24:213-9. 10.5435/JAAOS-D-15-00148

3. Arora M, Diwan AD, Harris IA: Burnout in orthopaedic surgeons: A review . ANZ J Surg. 2013, 83:512-5. 10.1111/ans.12292

4. Sargent MC, Sotile W, Sotile MO, Rubash H, Barrack R: Stress and coping among orthopaedic surgery residents and faculty. J Bone Jt Surgery-American Vol. 2004, 86:1579-86. 10.2106/00004623-20040700000032

5. Bedre V, Dadasaheb S, Smruti K, V Bedre V, Chachada A, Atulkar M: Professional burnout in orthodontistsan online survey report. IJOHMR. 2018, 3:36-7.

6. Shetty SH, Assem Y, Khedekar RG, Asha S, Arora M: Indian orthopaedic surgeons are less burned out than their Western colleagues. JAJS. 2017, 4:1-7. 10.1016/j.jajs.2017.03.005

7. Arora M, Diwan AD, Harris IA: Prevalence and factors of burnout among Australian orthopaedic trainees: A cross-sectional study. J Orthop Surg. 2014, 22:374-7. 10.1177/230949901402200322

8. Shanafelt TD, Boone S, Tan L, et al: Burnout and satisfaction with work-life balance among US physicians relative to the general US population. Arch Intern Med. 2012, 172:1377. 10.1001/archinternmed.2012.3199

9. Saleh KJ, Quick JC, Sime WE, Novicoff WM, Einhorn TA: Recognizing and preventing burnout among 


\section{Cureus}

orthopaedic leaders. Clin Orthop Relat Res. 2009, 467:558-65. 10.1007/s11999-008-0622-8

10. Chou L-P, Li C-Y, Hu SC: Job stress and burnout in hospital employees: Comparisons of different medical professions in a regional hospital in Taiwan. BMJ Open. 2014, 4:004185. Accessed: August 3, 2018:

10.1136/bmjopen-2013-004185

11. Gross CP, Mead LA, Ford DE, Klag MJ: Physician, heal thyself? Regular source of care and use of preventive health services among physicians. Arch Intern Med. 2000, 160:3209. 10.1001/archinte.160.21.3209

12. Shanafelt TD, Sloan JA, Habermann TM: The well-being of physicians . Am J Med. 2003, 114:513-9. 10.1016/S0002-9343(03)00117-7

13. Shanafelt TD: Finding meaning, balance, and personal satisfaction in the practice of oncology . J Support Oncol. 2005, 3:157-162.

14. Meier DE: The inner life of physicians and care of the seriously ill . JAMA. 2001, 286:3007. 10.1001/jama.286.23.3007 